\title{
Lean Six Sigma Methodologies and Organizational Profitability: A Review of Manufacturing SMEs in Nigeria
}

\author{
Okpala Kenneth Enoch \\ Department of Financial Studies (Accounting), Redeemer's University, Redemption City, Nigeria. \\ Email: kenenoch@yahoo.ca
}

Received August $3^{\text {rd }}, 2013$; revised September $3^{\text {rd }}, 2013$; accepted September $13^{\text {th }}, 2013$

Copyright (C) 2013 Okpala Kenneth Enoch. This is an open access article distributed under the Creative Commons Attribution License, which permits unrestricted use, distribution, and reproduction in any medium, provided the original work is properly cited.

\begin{abstract}
Manufacturing small- and medium-size enterprises (MSMEs) are reluctant to the implementation Lean and Six sigma methodologies (LSS) all the over world. This is traced to the impeding factors which seem stronger than motivating factors coupled with lack of proper documented evidence of LSS's successful implementation in many MSMEs. This paper investigated the influence of LSS on the profitability of MSMEs in Nigeria. The population of the study consists of 450 manufacturing SMEs with 2250 employees. The sample frame is made up of 225 MSMEs with 1026 staff selected at random upon which copies of structured questionnaire were administered. 1002 valid responses received were analyzed. Pearson product moment correction (PPMC) confirmed the formulated propositions with negative association between awareness, achievement CSFs and LSS implementation and the profitability level of MSMEs. The result obtained shows that LSS implementation among MSMEs in Nigeria is almost none existing and has no influence on the profit level. The study recommended that CEOs of MSMEs should undertake training on LSS to enable them to provide a strong leadership and support the initiative, LSS consultants should be engaged to help drive the quality improvement approach and MSMEs should focus on the impeding factors to reduce the effect on the LSS implementation and achieve continual quality improvement, customers' satisfaction, increase sales volume at a minimized cost to attain targeted market share and profit level.
\end{abstract}

Keywords: Lean Six Sigma; Critical Success Factors; Manufacturing SMEs; Impeding Factors; Profitability

\section{Introduction}

Profitability is the key motive behind every economic investment. Most financiers invest in business to address the issue of wealth maximization and shareholders' economic welfare [1]. Due to the complexity and the level of financial outlay involved in the establishment of large company, some investors resort to small or medium size firms (SMEs) which grow over time into medium or large organizations as the case may be [2]. The definition of SMEs varies globally with key criteria being number of employees and turnover of company [3]. In the UK and Europe, SMEs are firms with less than 250 employees according to European Commission in 2003 while Australian Bureau of Statistics in 2001 restricted SMEs to those firms having 200 employees or less. The Central Bank of Nigeria in its monetary policies circular No. 22 of 1988 described SMEs as those enterprises which has annual turnover not exceeding $=\mathrm{N}=500,000$. Experts maintained that no matter the definitional problem of SMEs, the concept and its contributions remained the same all over the world [4]. SME is a vital force in any nation and it is regarded as the engine of economic growth and development [5]. The sector has made significant contributions to Nigeria economy through helping the government to achieve some of its macro-economic objectives and enhancing growth and development $[6,3]$. Their significance is obvious in creating new competition, reducing poverty, generating gainful employments for employable citizens and boosting national turnover and GDP development $[7,8]$. Though the awareness of the contribution of SMEs is becoming prevalent among nations, their importance is greatly undervalued [9]. Today, most governments are focusing on SMEs as a means of providing solutions to some economic problems. Application of Lean Six Sigma (LSS) for establishing continuous quality improvement especially in the manufacturing subsector, is recently on the increase in the advanced countries and to a large extent seems to have become a permanent approach adopted by organizations that want compete globally and have financial 
stability. LSS represents an amalgamation of two improvement concepts that have been used by large organizations with standing success story such as Motorola, General Electric, Honeywell and many others [10]. Lean manufacturing was initiated in Japan at a time when SSM has been successfully tested and benefits established. The initial concern was that since both programmes operate at different aspect of a manufacturing organization with the similar goals, how could both approaches be merged towards one improvement methodology? [11]. Snee suggested that LSS experts should rather focus on the integration of the approach to ensure that both the production line and management achieves total quality improvements rather than unfruitful debate. Studies conducted on LSS methodologies were particularly designed for large organizations [11] but this research is carried out to study the relevance and the direct application of LSS to SMEs. This triggered off the need to probe the underlying principles behind the approach to establish how quality management affects profitability in manufacturing SMEs' context.

\subsection{Statement of Problem and Research Hypotheses}

Poor profitability of SMEs has been traced to derisory human capital in production and management units, obsolete technologies, lack of adequate finance and inability to apply modern management techniques [5]. The issues of modern management techniques limitation such as the implementation of Lean and Six Sigma programmes in many ways affected the quality of products and management services which in turn have reduced SMEs organizational share of market through customers' dissatisfaction [12] and influenced the resulting profit [11]. Previous studies on LSS implementation in manufacturing SMEs in UK, The Netherland, Australia, and Belgium are well documented in the literature $[11,13,14]$ however to the best this researcher's knowledge, there is little or no study conducted to link LSS implementation to organizational profitability which prompted this research work to enable harmonization and proper documentation. The major objective of this paper is to assess the effect of LSS implementation on profitability of manufacturing SMEs in Nigeria. Subsidiary objectives to be investigated include: 1) to establish the level of awareness and understanding of LSS implementation in manufacturing SMEs in Nigeria and 2) to examine the critical success and impeding factors from a manufacturing SMEs standpoint in Nigeria. In order to accomplish the objectives set for the study, the research questions raised to be addressed are: $\mathbf{R} \mathbf{Q}_{\mathbf{1}}$ : what is the degree of awareness and understanding of LSS implementation in Nigeria manufacturing SMEs? $\mathbf{R Q}_{2}$ : how does the achievement of critical success factors (CSF) motivate the LSS implementation in manufacturing SMEs in Nigeria? $\mathbf{R Q}_{3}$ : to what extent has LSS implementation influenced the profit level of manufacturing SMEs in Nigeria? The formulated hypotheses are $\mathbf{H 0}_{\mathbf{1}}$ : There is no significant association between awareness and LSS implementation in Nigeria MSMEs $\mathbf{H O}_{2}$ : critical success factors have not significantly motivated LSS implementtation in Nigeria manufacturing SMEs $\mathrm{HO}_{3}$ : LSS implementation has not significantly influenced profitability of manufacturing SMEs in Nigeria.

\subsection{Model Specifications}

There are two key criterion variables upon which this study needs to focus. They are of LSS implementation and profitability of manufacturing SMEs in Nigeria. The predictor variable - Quality Improvement referred to as a Lean Six Sigma-LSS is (Y), while Profitability is (X). In order to test the hypotheses, the Regression analysis model below is developed by the researcher. The moderating variables are listed as equation below:

$$
\begin{aligned}
& \mathrm{Y}=\mathrm{f}(\mathrm{X}) ; \mathrm{X}=\mathrm{f}\left(\mathrm{X}_{1}, \mathrm{X}_{2}, \mathrm{X}_{3}, \mathrm{X}_{4}, \text { and } \mathrm{X}_{5}\right) \\
& \mathrm{Y}=\mathrm{X}_{0}+\mathrm{X}_{1} \mathrm{CBS}+\mathrm{X}_{2} \mathrm{MC}+\mathrm{X}_{3} \mathrm{SR}+\mathrm{X}_{4} \mathrm{WP}+\mathrm{X}_{5} \mathrm{CS}
\end{aligned}
$$

$$
\begin{gathered}
\mathrm{Y}_{1}=\mathrm{X}_{1} \mathrm{CBS} \\
\mathrm{Y}_{2}=\mathrm{X}_{2} \mathrm{MC} \\
\mathrm{Y}_{3}=\mathrm{X}_{3} \mathrm{SR} \\
\mathrm{Y}_{4}=\mathrm{X}_{4} \mathrm{WP} \\
\mathrm{Y}_{5}=\mathrm{X}_{5} \mathrm{CS}
\end{gathered}
$$

In order to test the hypotheses $\mathrm{HO}_{3}$, which is the subject matter of the research, a multiple regression model for this study is given as:

$$
\begin{aligned}
\mathrm{Y}= & \beta 1 q i_{s} \mathrm{CBS}+\beta 2 q i_{s} \mathrm{MC}+\beta 3 q i_{s} \mathrm{SR} \\
& +\beta 4 q i_{s} \mathrm{WP}+\beta 5 q i_{s} \mathrm{CS}
\end{aligned}
$$

where: $\mathrm{Y}=$ Lean Six Sigma Methodologies; $\mathrm{CBS}=$ Current Business System; $\mathrm{MC}=$ management commitment; $\mathrm{SR}=$ size of resources; $\mathrm{WP}=$ workers participation; and $\mathrm{CS}=$ Customers' satisfaction. $\mathrm{Y}=1$, if LSS positively influence profitability in Nigeria and If not $\mathrm{Y}=0$

\subsection{Basis of the Study}

The basis of this study is to evaluate the association between LSS implementation of manufacturing SMEs and the resulting profitability. The effect of the moderating factors such as the CSFs is also considered an explanatory variable predicting profitability of manufacturing SMEs. In addition, LSS implementation result is directly related to impeding factors which limit the achieve- 
ments. If a company focuses on the improvement of the quality of products and work flow through management, there will be customers' satisfaction leading to increase in turnover, cost minimization and a higher level of profitability attainment. It is therefore assumed that if manufacturing SMEs make quality improvement a priority, desired profit level would be achieved.

\section{Review of Related Literature}

\subsection{Theoretical Framework}

The theoretical foundation of this study is based on the work of Snee [11] which states that the Lean six sigma is a well structured theory based methodology implemented to improve performances, develop effective leadership, achieve customer satisfaction and bottom line results. Lean manufacturing and six sigma together became very powerful and eliminates waste in each aspect of production and management procedures. It applies tools and techniques of both Lean manufacturing and six sigma (DMAIC and DMADV) in manufacturing business environment to achieve quality and bottom line results. The major reason for implementation of LSS is to provide a foundation for quality improvement, competitive pricing and increase profit margins. Lean Six Sigma is a business strategy and methodology that increases process performance resulting in enhanced customer satisfaction and improved bottom-line results [15]. The conceptual model for LSS and profitability is shown in Figure 1 below.

\subsection{Lean Six Sigma Methodologies}

Lean manufacturing (LM) and six sigma methodology (SSM) are separate and unique programmes that have similar goals and end results. The combination of LM and SSM into a batch gave birth to single methodology referred to as Lean Six Sigma (LSS) which yields maximum result [10]. Adopting and implementing LSS is akin to the implementation of change management process in manufacturing environment. The manufacturing side (Lean) and procedural side (Six Sigma) will bring about a methodology capable of infusing positive significant changes towards better quality products and services, more rapid result as well as more productive workers and higher profit margin which will benefit all stakeholders [16]. Lean manufacturing was a Japanese invention, inspired by a plant tour of Ford Motors in the 1950s. After watching an American assembly plant build cars in a more efficient way, two Japanese executives developed the Toyota Production System (TPS). This approach propelled Toyota from a modest domestic firm to a global car giant. While most of the car industry suffered from dwindling economy, Toyota recorded a net income increase of $23.2 \%$ in the interim account of September 2003 in comparison with the same period of the previous financial year from $8 \%$ increase in turnover [17]. Lean manufacturing became popular after the publication of the books "The Toyota Production System" [17,18]. Lean ideologies expanded beyond Japanese car making to other industries and around the world. Today, most manufacturing multinational organizations in Europe,

Asia and other continents are using lean programs especially U.S. carmakers taking a lead. Other industries are waking up to the new opportunity $[11,5]$. Six sigma is a logical and methodical approach designed to achieving disciplined quality improvements in areas critical to the success of any service-oriented organization-management procedures [13]. It was originally developed by Motorola in 1986 and used to win the 1988 Malcolm Baldrige National Quality Award and within the first five years, achieved profit level of \$US2.2 billion [19]. SSM became well known after Jack Welch made it a central focus of his business strategy at General Electric in 1995 and the approach became a leading procedural quality improvement programme [20]. SSM is used to achieve total quality management (TQM) when added to the current business system (CBS). This can be expressed mathematically as:

$$
\mathrm{CBS}+\mathrm{SSM}=\mathrm{TQM}
$$

The combination of Lean and Six Sigma principles in manufacturing efforts is to ensure flawless product quality and repeatable execution which will help producers to deliver value to customers in a repeatable manner. This

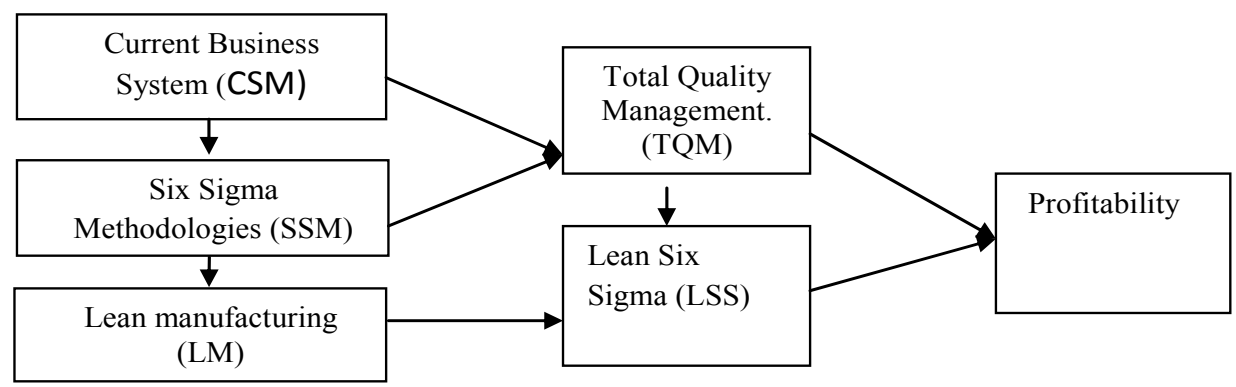

Figure 1. Conceptual framework of LSS and profitability. Source: Author's conceptualization 2013. 
technical marriage of two quality management approaches-Lean manufacturing (LM) and Six sigma methodology (SSM) can be expressed mathematically as:

$$
\mathrm{LM}+\mathrm{TQM}=\mathrm{LSS}
$$

If the two are actually implemented in isolation, the outcome can result in either being ineffectiveness or constrained by one another's needs and could also create two subcultures within the organisation competing for the same resources [21]. Any attempt to implement only one of the processes, will drag the manufacturing organization into grievous production and management dilemma in the sense that when production is streamlined, management may not understand the reason behind additional costs and when management is restructured, production area does not understand the changes. Therefore a combination and simultaneous implementation of both programmes is essential so that LM targets changes in production line while SSM works on process flow through management [10]

\subsection{Critical Success Factors and Challenges to Implementation of LSS in Manufacturing SMEs}

Critical Success Factors (CSFs) are those factors which are critical to the success of any organisation in the sense that if objectives associated with the factors are not achieved, the organisation will fail woefully [7,22]. Studies conducted in the UK and Australian shows that there is a huge gap between the perceived CSFs and practice which has resulted in the poor organizational performance of SMEs. The factors identified as critical in the success of manufacturing SMEs LSS implementation are: 1) Strong leadership; 2) management commitment; 3) adequate skilled workforce; 4) awareness and understanding of LSS; 5) Customer satisfaction; 6) financial viability \& infrastructure. Lastly collaboration with government bodies and local universities or research outfits to learn more about the development in the field of quality management $[3,23]$. The barriers impeding the implementation of LSS include: 1) Lack of resources; 2) Lack of training; 3 internal resistance [12,14,24,25]; 4) lack of knowledge and poor employee participation and 5) lack of top management commitment $[23,26]$.

\subsection{Manufacturing SMEs and Product Improvement}

Standing on the definition of SMEs in Nigeria context according to Central Bank of Nigeria's monetary policies circular No. 22 of 1988, it means that manufacturing SMEs are those enterprises producing goods within various sectors and whose turnover is not more than $=\mathrm{N}$ $=500,000$. They are found mostly in food, cloth making, plastic manufacturing, woodwork and iron fabrication industry. In manufacturing sector, consideration of product design is essential before adopting any improvement process because the design may create some problems if not well handled. $70 \%$ of the costs of a product are locked up at the design stage. The opportunity for manufacturing cost savings through better technology, genuine materials, and processes is tremendous and should be captured before process improvements [27]. Product improvements can come about through standardization of the product, common subassemblies and parts, utilization of the principles of design for manufacturing (DFM), design for assembly (DFA), flattening of bills of materials, and seeking advantages for the product line through the theory of inventive problem-solving (TRIZ). Implementation of all the above is within the content of lean which reducing waste in inventory and production [3].

\subsection{The Impact of Lean Six Sigma on Profitability}

The benefits of LSS initiatives to the implementing SME organizations is based on the elimination of waste and errors in production line and procedural workflow; ensure flawless product quality, improvement on the existing system; delivery of value to customers in a repeatable manner leading to satisfaction. These benefits have direct association with profit maximization. Elimination of waste will reduce production cost in terms of materials, time saving in workflow while improved quality encourages consumption, enhances sales volume and organizational share of market. Profit is a function of costs minimization and sale volume and this can be expressed as equation below:

$$
\mathrm{P}=\mathrm{f}(\mathrm{CQM}+\mathrm{SV})
$$

where cost minimization embodies flattering cost materials, labour and direct expense and sales volume is in response to customers' satisfaction and market price. Four major studies conducted were done in Belgium, Australia, UK and The Nederlands. All of them showed a high key performance metrics after the implementation of the LSS by manufacturing SMEs. However, the realization of benefits in the Netherland SMEs is slight less compared to their Australian and UK counterpart [12]. One of the challenges reported by SMEs in Europe was difficult to quantify benefits from LSS. According to Kumar [3], it was suggested that manufacturing SMEs should involve Accounting and Finance Department staff in carry out the cost-benefit analysis (CBA) before and after the LSS implementation to track the level of improvement in their established performance metrics. The competitive advantage is a source for sustainable success of the organizations. Sustainable success of an organization is achieved through its ability to meet the needs and expec- 
tations of its customers and other stakeholders in the long term [28].

\section{Methodology}

Research Design: This research adopted a mix method of literature review approach and a across sectional survey of manufacturing SMEs in Nigeria as used in Andreea, Sorin \& Mihai [15]. A structured approach was adopted to investigate the published literature regarding lean six sigma from the well established research databases which include: Emerald, Google scholar, Science direct and EBSCO host as adaptation of the method used by Qun, Xiaoning and Mahmood [29]. A total of 62 research papers were reviewed and the criteria for the literature selected for investigation are: 1) articles published in English language only; 2) lean manufacturing, six sigma methodology or combination of both; 3) They are either theories and case studies and 4) the content scope of the study involved 10 years between 2003 to 2012. Survey research method which is a classical methods for researchers to statistically validates research questions and hypothesis the field of Quality Management $[8,27,30]$, was used for data gathering from respondents through a structured questionnaire [31,32].

Population: The total population of this study is made up of 450 SMEs as shown in Table 1 that meets the following criteria: 1) should be a manufacturing organization; 2) have employees of 200,000 or less; 3) have turnover not exceeding $=\mathrm{N}=500,000 ; 4$ ) have established a system with common infrastructure; 5) must have normal departments with management team comprising five key officers as follows: Management Director, General manager, Accountants, Production Manager, and Administrative Manager. Giving a total population of 2250 employees purposively selected to represent their organization as stated in Table 1. These firms were extracted from the database, directories of manufacturing SMEs associations and register of Manufacturing Association of Nigeria (MAN)

Participants: The sample frame consists of 1026 staff representing 50\% located in three major zones North, East and Western part of Nigeria. Two industrial cities from each zone of the country are: Lagos $(\mathrm{Lg})$ and Ibadan (Ib) from West, Abuja (Ab) and Kaduna (Kd) from the North and Anambra (An) and Port Harcourt (Ph) from the East. The employment of sample population of $50 \%$ is to have excellent result according to Comfrey \& Less [33] and the total valid responses of 1002 shown in Table 2 were received representing 98\% which is considered excellent.

Table 1. Population of the study (Manufacturing SMEs) by Zone.

\begin{tabular}{|c|c|c|c|c|c|c|c|c|c|}
\hline Zone & PMC & Ab & Kd & An & $\mathbf{P h}$ & Lg & Ib & Total & Percent. (\%) \\
\hline 1 & Northern Zone & 34 & 16 & & & & & 50 & $11 \%$ \\
\hline 2 & Eastern Zone & & & 146 & 25 & & & 171 & $38 \%$ \\
\hline 3 & Western Zone & & & & & 165 & 64 & 229 & $51 \%$ \\
\hline Total & & 34 & 16 & 146 & 25 & 165 & 64 & 450 & $100 \%$ \\
\hline
\end{tabular}

Source: Field work, 2013.

Table 2. Summary of response from the sample frame distributed by Zone.

\begin{tabular}{|c|c|c|c|c|c|c|c|c|c|}
\hline Zone & PMC & Ab & Kd & An & $\mathbf{P h}$ & Lg & Ib & Total & Percent. (\%) \\
\hline 1 & Northern Zone & 71 & 32 & & & & & 103 & $10 \%$ \\
\hline 2 & Eastern Zone & & & 322 & 58 & & & 171 & $38 \%$ \\
\hline 3 & Western Zone & & & & & 383 & 136 & 229 & $52 \%$ \\
\hline Total & & 71 & 32 & 322 & 58 & 383 & 136 & 1,002 & $100 \%$ \\
\hline
\end{tabular}

Source: Field work, 2013. 


\section{Results and Discussion}

\subsection{Test of Statistical Hypotheses}

Table 3. Summary of test results.

\begin{tabular}{|c|c|c|c|c|c|c|c|}
\hline \multirow{2}{*}{ Нyро. NO } & \multirow{2}{*}{ Statement of Hypothese } & \multirow{2}{*}{ RQ } & \multicolumn{3}{|c|}{ Test Results } & \multirow{2}{*}{ Degree of Corr. } & \multirow{2}{*}{ Decisions } \\
\hline & & & Cal "r" & $\operatorname{LS}(\mathrm{x})$ & Infer. & & \\
\hline 1 & $\begin{array}{l}\text { There is no significant association } \\
\text { between awareness and LSS imple- } \\
\text { mentation in Nigeria MSMEs }\end{array}$ & $1,2 \& 3$ & -0.16 & 0.5 & $\mathrm{r}<\mathrm{x}$ & Negative & Accept $\mathrm{H}_{0}$ Do not accept $\mathrm{H}_{1}$ \\
\hline 2 & $\begin{array}{l}\text { Critical success factors have not } \\
\text { significantly motivated LSS mple- } \\
\text { mentation in Nigeria SMEs }\end{array}$ & $4,5 \& 6$ & -0.15 & 0.5 & $\mathrm{r}<\mathrm{x}$ & Negative & Accept $\mathrm{H}_{0}$ Do not accept $\mathrm{H}_{1}$ \\
\hline 3 & $\begin{array}{l}\text { LSS implementation has not signifi- } \\
\text { cantly influenced profitability of } \\
\text { manufacturing SMEs in Nigeria }\end{array}$ & $\begin{array}{l}7,8,9,10 \\
11 \& 12\end{array}$ & -0.14 & 0.5 & $\mathrm{r}<\mathrm{x}$ & Negative & Accept $\mathrm{H}_{0}$ Do not accept $\mathrm{H}_{1}$ \\
\hline
\end{tabular}

Source: Field work, 2013.

\subsection{Discussion of Result in Table 3}

Hypothesis 1: hypothesis 1 tested the relationship between awareness of LSS and its implementation and was tracked by question 1, 2 and 3 of questionnaire administered: What is the level of awareness and understanding of LSS methodology in Nigeria manufacturing SMEs? What is the degree of LSS implementation in your organization? And how many years experience do you have gain in LSS implementation? Table 4 shows a total of 1002 valid responses received and analyzed with 898 low and 71 slightly low to rank $1^{\text {st }}$ and $2^{\text {nd }}$. In Table 5, the calculated " $r$ " of -0.16 at $5 \%$ level of significance shows an absolute lack of awareness and understanding of LSS among manufacturing SMEs in Nigeria. Therefore the null hypothesis which states that there is no significant association between awareness and LSS implementation in Nigeria MSMEs is accepted and alternate rejected. This total ignorance of the concept is responsible for the little or no implementation of the programme and this was confirmed by question 3 of questionnaire which asked the respondents to state the number of years experience gain in the LSS programme implementation process. Apart from three respondents, none had any experience on approach. The three respondents that voted high and slightly high were staff of manufacturing SME that is a subsidiary of large parent companies in USA and Europe. From the data collected and analyzed, the correlation between LSS awareness and implementation in MSMEs in Nigeria is negative. It means that only few MSMEs representing $1.2 \%$ of the source list have actually implemented LSS. Some of the reasons apart from lack of awareness and understanding are: managements are afraid of the unknown, staff resistance to change management, lack of skill workers with knowledge of LSS and no expert to drive the initiative. This result is in agreement with the opinion of Kumar and Antony;
Kumar, Khurshid, Manoj, Timans, et al.; Qun et al. [12,26,29].

Hypothesis 2: This linked CSFs to the implementation of LSS and was tracked by Questions 4, 5 and 6 of questionnaire administered. Out of 1002 valid responses received and analyzed, 860 were low and 78 slightly low to rank $1^{\text {st }}$ and $2^{\text {nd }}$ as shown in Table 6 which signified the presence of demotivation. From the questionnaire administered and responses received, all the CSFs are considered important but because management failed to achieve them, the implementation of LSS failed woefully. This is evident by the calculated " $r$ " of -0.15 at $5 \%$ level of significance shown in Table 7. Null hypothesis 2 which says that critical success factors have not significantly motivated LSS implementation in Nigeria manufacturing SMEs is accepted and alternate not accepted. This result confirmed the opinion of Rockart, Yusof and Aspinwall [7,22]. In Nigeria, manufacturing SMEs were unable to provide strong leadership, management were not committed due to fear, adequate skilled workforce with understanding of LSS concept are not available, inadequate resources and infrastructure to achieve the programme prevailed. All these militated against LSS quality improvement approach and as a result, customers' satisfaction was not achieved leading to market failure and poor profitability level. Few MSMEs attempted implementation but were constrained by few workers doing multiple tasks and were afraid of transformation hence resisted and frustrated the change management. The result obtained is in accordance with studies conducted in the UK and Australian which shows that there is a huge gap between the perceived CSF and practice leading to MSMEs poor organizational performance [23,25].

Hypothesis 3: This is captured using multiple questions 7 to 12 with average response computed to achieve the result in Table 8. Questions 12 was used to track the proposition and out of total of 1002 valid responses re- 
ceived 408 were average slightly low and 225 average low to rank $1^{\text {st }}$ and $2^{\text {nd }}$ Table 9 shows the calculated " $r$ " of -0.14 at $5 \%$ level of significance which confirms that non LSS implementation was responsible for the $14 \%$ negative variation in profitability level-losses of MSMEs. The null hypothesis which says that there is has no significant association between LSS implementation and profitability of manufacturing SMEs in Nigeria is hereby accepted and the alternate not accepted.

\subsection{Contribution to Knowledge}

To the best of the researcher's knowledge no study has been able to link LSS implementation to profitability in manufacturing SMEs in Nigeria. Therefore, this exploratory research result has contributed to knowledge in this direction. It is obvious that Nigeria MSMEs are neither aware nor had understanding of LSS implementation, CSFs achievement failed woefully and the envisaged profitability level from the programme is not achieved.

\section{Findings}

Based on the result in the above section, the following findings were obtained: 1) there is no awareness and understanding of LSS among manufacturing SMEs which is one of the factors responsible for no implementation; 2) CSFs such as adequate resources, expertise, management support, and committed workers were not achieved; 3) In Nigeria, most manufacturing SMEs' quality management experience is limited to ISO 9000 certification which should have been the beginning of quality improvement journey. These findings are in agreement with research conducted in UK, The Nederlands and Australia $[6,7,26]$; 4) The study also revealed that the contribution of quality management is not in any way significant due to little or no implementation of LSS; 5) most firms stated that Nigeria have no expert to drive continuous improvement effort. This is in agreement with the opinion of Thomas and Webb [34]; 6) ISO standards facilitates basic understanding towards quality management and encourage the continual improvement leading to adoption of advanced Q M methodologies such as LSS [12]; 7) The study also revealed that customer complaints which is the most active feedback mechanism in the advance countries are ineffective in Nigeria environment. The findings reported in this study are in agreement with academic literature and the opinion of Antony et al.; Kumar and Antony and Achanga et al. [14,26,35]

\section{Conclusion}

The study concluded that since the LSS manufacturing SMEs have not been implementation in MSMEs in Nigeria, the approach could not moderate profitability. The study therefore recommends that: 1) CEOs of MSMEs should undertake training on quality improvement to enable them to provide a strong leadership and support the initiative; 2) LSS consultants should be employed to help them drive the quality improvement; 3) MSMEs should focus on the impeding factors to reduce the effect on the LSS implementation. This will help achieve continual quality improvement, cost minimization, customers' satisfaction, increase in sales volume and achievement targeted profit.

\section{Limitations and Directions for Further Studies}

One of the challenges reported by SMEs in Europe was the difficulty experienced in measuring and quantifying the benefits flowing from LSS implementation [3]. The author did not cover lean accounting therefore suggested that further study be conducted on it. This will enable the determination of the benefits of Lean activity by appraising the value stream and establishing the level of improvement and their performance metrics [3]

\section{REFERENCES}

[1] O. Akinsulire, "Financial Management," 4th Edition, EL-Toda Venture Press, Lagos, 2010.

[2] I. M. Pandey and K. L. W. Parera, "Determinants of Effective Working Capital Management: A Discriminated Analysis Approach," Research and Publication Department Indian Institute of Management, Iima Working Paper No. 1349, 1997.

[3] M. Kumar, "Six Sigma Implementation in UK Manufacturing SMEs: An Exploratory Research," Ph.D. Thesis, University of Strathclyde, Glasgow, 2010.

[4] K. E. Okpala, "Venture Capital and the Emergence and Development of Entrepreneurship: A Focus on Employment Generation and Poverty Alleviation in Lagos State," CS Canada, International Business and Management, Vol. 5, No. 2, 2012, pp. 134-141.

[5] K. E. Okpala, "Total Quality Management and SMPS Performance Effects in Nigeria: A Review of Six Sigma Methodology," Asian Journal of Finance \& Accounting. Vol. 4, No. 2, 2012, pp. 363-378. http://dx.doi.org/10.5296/ajfa.v4i2.2641

[6] A. Ghobadian and D. N. Gallear, "Total Quality Management in SMEs," Omega: International Journal of Management Science, Vol. 24, No. 1, 1996, pp. 83-106.

[7] S. M. Yusof and E. Aspinwall, "Critical Success Factors in Small and Medium Enterprises, Survey Results," Total Quality Management, Vol. 11, No. 4-6, 2000, pp. S448S462.

[8] J. Antony, M. Kumar and A. Labib, "Gearing Six Sigma into UK Manufacturing SMEs: Empirical Assessment of Critical Success Factors, Impediments, and Viewpoints of Six Sigma implementation in SMEs," Journal of Op- 
eration, Research Society, Vol. 59, No. 4, 2008, pp. 482493. http://dx.doi.org/10.1057/palgrave.jors.2602437

[9] J. North, R. Blackburn and J. Curran, "The Quality Business Quality Issues in the Smaller Firm," Routledge, London, 1998

[10] W. Timans, J. Antony, K. Ahaus and R. Van Solingen, "Implementation of Lean Six Sigma in Manufacturing SME Enterprises in the Nether Lands," Journal of the Operational Research Society, Vol. 63, 2012, pp. 339-353. http://dx.doi.org/10.1057/jors.2011.47

[11] R. D. Snee, "Lean Six Sigma-Getting Better All the Time," International Journal of Lean SixSigma, Vol. 1, No. 1, 2010, pp. 9-29. http://dx.doi.org/10.1108/20401461011033130

[12] M. Kumar and J. Antony, "Multiple Case Study Analysis of Quality Management Practice within UK Six Sigma and Non-Six Sigma Manufacturing Small- and MediumSized," Journal of Engineering Manufacture, Vol. 223, No. 7, 2009, pp. 333-351. http://dx.doi.org/10.1243/09544054JEM1288

[13] B. Wyper and A. Harrison, "Deployment of Six Sigma Methodology on Human Resources Function: A Case Study," Total Quality Management, Vol. 11, No. 495, pp. 720-727. http://dx.doi.org/10.1080/09544120050008129

[14] M. Kumar and J. Antony, "Comparing the Quality Management Practices in UK SMEs," Industrial Management and Data Systems, Vol. 108, No. 9, 2008, pp. 1153-1166. http://dx.doi.org/10.1108/02635570810914865

[15] J. P. Andreea, A. Sorin and D. Mihai, "Lean Six SigmaA Challenge for Organizations Focused on Business Excellence," The Romanian Economic Journal. Vol. 14, No. 41, 2011, pp. 147-158.

[16] M. K. Tiwari, J. Antony and D. C. Montgomery, "Editorial Note for the Special Issue on Effective Decision Support to Implement Lean and Six Sigma Methodologies in the Manufacturing and Service Sectors", International Journal of Production Research, Vol. 46, No. 23, 2008, pp. 6563-6566. http://dx.doi.org/10.1080/00207540802230041

[17] T. Ohno, "The Toyota Production System: Beyond LargeScale Production," Portland, Productivity Press 1998.

[18] S. Shingo, "A Study of the Toyota Production System," Productivity Press, New York, 1989.

[19] T. Lucey, "Quantitative Techniques," 6th Edition," Book Power, London, 2002

[20] K. M. Henderson and J. R. Evans, "Successful Implementation of Six Sigma," Benchmarking General Electric Company," Benchmarking, An International Journal, Vol. 7, No. 4, 2000, pp. 260-282.

[21] M. P. J. Pepper and T. A. Spedding, "The Evolution of Lean Six Sigma," International Journal of Quality \& Reliability Management, Vol. 27, No. 2, 2010, pp. 138-155. http://dx.doi.org/10.1108/02656711011014276

[22] J. Rockart, "Chief Executives Define Their Own Data Needs," Harvard Business Review, Vol. 57, No. 2, 1979 , pp. 238-241.
[23] M. Kumar, "Critical Success Factors and Hurdles to Six Sigma Implementation: The Case of a UK Manufacturing SME," International Journal of Six Sigma and Competitive Advantage, Vol. 3, No. 4, 2007, pp. 333-351. http://dx.doi.org/10.1504/IJSSCA.2007.017176

[24] A. Thomas, R. Barton and C. Chuke-Okafor, "Applying Lean Six Sigma in a Small Engineering Company-A Model for Change," Journal of Manufacturing Technology Management, Vol. 20, No. 1, 2009, pp. 113-129. http://dx.doi.org/10.1108/17410380910925433

[25] D. Van Goubergen, M. Dora, M. Kumar, A. Molnar and X. Gellynck, "Lean Application among European Food SMEs: Findings from Empirical Research," Industrial Engineering Research Conference. IIE, Reno, 2011.

[26] J. Antony, M. Kumar and C. N. Madu, "Six Sigma in Small- and Medium-Sized UK Manufacturing Enterprises: Some Empirical Observations," International Journal of Quality \& Reliability Management, Vol. 22, No. 8, 2005, pp. $860-874$. http://dx.doi.org/10.1108/02656710510617265

[27] M. Kumar, K. K. Khurshid, K. D. Manoj, W. Timas, and J. Anton, "Lean/Six Sigma Implementation in SMEs: Key Findings from International Research," 4th Joint World Conference on Production \& Operations Management/ 19th International Annual European OMA Conference, Amsterdam, 1-5 July 2012.

[28] T. Sava, C. Rizea (Pirnea) and I. Flood, "Benefits of the Implementation and Certification for Environmental Management System SMEs in Romania," Quality-Access to Success Journal, Vol. 2, 2010, pp. 248-254.

[29] Z. Qun, Z. Xiaoning and H. Mahmood, "Lean Six Sigma: A Literature Review," Interdisciplinary Journal of Contemporary Research in Business. Vol. 3, No. 10, 2012, pp. 599-605.

[30] M. G. Aboelmaged, "Six Sigma Quality: A Structured Review and Implications for Future Research", International Journal of Quality \& Reliability Management, Vol. 27, No. 3, 2010, pp. 269-318. http://dx.doi.org/10.1108/02656711011023294

[31] M. Saunders, P. Lewis and A. Thornhill, "Research Methods for Business Students," 5th Edition, Prentice Hall, Essex, 2010.

[32] F. J. Fowler, "Survey Research Methods," 3rd Edition, London," Sage Publication, New York, 2002.

[33] A. L. Comfrey and H. B. Lee, "A First Course in Factor Analysis," Lawrence Erlbaum Associates, Hillsdale, 1992.

[34] A. J. Thomas and D. Webb, "Quality Systems Implementation in Welsh Small-to Medium-Sized Enterprises: A Global Comparison and a Model for Change," Journal of Engineering Manufacture, Vol. 217, No. 4, 2003, pp. 573-579. http://dx.doi.org/10.1243/095440503321628251

[35] P. Achanga, E. Shehab, R. Roy and G. Nelder, "Critical Success Factors for Lean Implementation within SMEs," Journal of Manufacturing Technology Management, Vol. 17, No. 4, 2006, pp. 460-471. http://dx.doi.org/10.1108/17410380610662889 


\section{Appendix 1}

\section{Hypothesis 1}

$\mathrm{H}_{0}$ : There is no significant association between awareness and LSS implementation in Nigeria M SMEs

$\mathrm{H}_{1}$ : There is significant association between awareness and LSS implementation in Nigeria M SMEs

Table 4. Summary of responses on key issue linking awareness and LSS implementation in MSMEs in Nigeria.

\begin{tabular}{ccccccccc}
\hline Sample Strata & High (6) & Slightly High (5) & Medium (4) & Slightly Low (3) & Low (2) & No Influ. (1) & No Opin. (0) & Total \\
\hline Zone - North & 0 & 0 & 2 & 9 & 58 & 2 & $\mathbf{7 2}$ \\
Zone 2 - East & 1 & 1 & 4 & 24 & 377 & 7 & 4 & $\mathbf{4 1 8}$ \\
Zone 3 - West & 0 & 1 & 3 & 38 & 463 & 5 & 2 & $\mathbf{5 1 2}$ \\
Total & 1 & 2 & 9 & 71 & 898 & 14 & 7 & $\mathbf{1 0 0 2}$ \\
Percentage (\%) & $\mathbf{0 . 1 \%}$ & $\mathbf{0 . 2 \%}$ & $\mathbf{0 . 9 \%}$ & $\mathbf{7 . 1 \%}$ & $\mathbf{8 9 . 6 \%}$ & $\mathbf{1 . 4 \%}$ & $\mathbf{0 . 7 \%}$ & $\mathbf{1 0 0 \%}$ \\
Ranking & $\mathbf{7}^{\text {th }}$ & $\mathbf{6}^{\text {th }}$ & $\mathbf{4}^{\text {th }}$ & $\mathbf{2}^{\text {nd }}$ & $\mathbf{1}^{\text {st }}$ & $\mathbf{3}^{\text {rd }}$ & $\mathbf{5}^{\text {th }}$ \\
\hline
\end{tabular}

Source: Field work (2013). Question 1, 2, and 3 of the questionnaire administered.

Table 5. Calculation of correlation.

\begin{tabular}{ccccccccc}
\hline Options & High (6) & Slightly High (5) & Medium (4) & Slightly Low (3) & Low (2) & No Influ. (1) & No Opin. (0) & Total \\
\hline Points (x) & 6 & 5 & 4 & 3 & 2 & 1 & 0 & $\mathbf{2 1}$ \\
Response (y) & 1 & 2 & 9 & 71 & 898 & 14 & 7 & $\mathbf{1 0 0 2}$ \\
$\mathbf{x y}$ & 6 & 10 & 36 & 213 & 1796 & 14 & 0 & $\mathbf{2 0 7 5}$ \\
$\mathbf{x}^{2}$ & 36 & 25 & 16 & 9 & 4 & 14 & 0 & $\mathbf{1 0 4}$ \\
$\mathbf{y}^{2}$ & 1 & 4 & 81 & 5,041 & 806,404 & 196 & 49 & $\mathbf{8 1 1 , 7 7 6}$ \\
\hline
\end{tabular}

Source: Field work (2013).

$$
\begin{aligned}
r & =\frac{N \sum x y-\left(\sum x\right)\left(\sum y\right)}{\sqrt{N \sum x^{2}-(x)^{2}} \sqrt{N \sum y^{2}-(y)^{2}}}=\frac{7(2075)-(21 \times 1002)}{\sqrt{(7 \times 104)-(21)^{2}} \sqrt{7 \times 811776-(104)^{2}}} \\
& =\frac{14525-21042}{\sqrt{(728-441)(5682432-10816)}}=\frac{-6517}{\sqrt{(287)(5671616)}}=\frac{-6517}{40345} \quad r=-0.1615(16 \%)
\end{aligned}
$$

\section{Hypothesis 2}

$\mathrm{H}_{0}$ : Critical success factors has not significantly motivated LSS implementation in Nigeria manufacturing SMEs
$\mathrm{H}_{1}$ : Critical success factors have significantly motivated LSS implementation in Nigeria manufacturing SMEs

Table 6. Summary of responses on key issue linking CSF to LSS implementation in MSMEs in Nigeria.

\begin{tabular}{ccccccccc}
\hline Sample Strata & High (6) & Slightly High (5) & Medium (4) & Slightly Low (3) & Low (2) & No Influ. (1) & No Opin. (0) & Total \\
\hline Zone - North & 2 & 2 & 4 & 10 & 50 & 2 & 2 & 72 \\
Zone 2 - East & 5 & 8 & 2 & 23 & 369 & 5 & 6 & $\mathbf{4 1 8}$ \\
Zone 3 - West & 7 & 3 & 4 & 45 & 441 & 9 & 3 & $\mathbf{5 1 2}$ \\
Total & $\mathbf{1 4}$ & $\mathbf{1 3}$ & $\mathbf{1 0}$ & $\mathbf{7 8}$ & $\mathbf{8 6 0}$ & $\mathbf{1 6}$ & $\mathbf{1 1}$ & $\mathbf{1 0 0 2}$ \\
Percentage (\%) & $\mathbf{1 . 4}$ & $\mathbf{1 . 3 \%}$ & $\mathbf{1 . 0 \%}$ & $\mathbf{7 . 8 \%}$ & $\mathbf{8 5 . 8 \%}$ & $\mathbf{1 . 6 \%}$ & $\mathbf{1 . 1 \%}$ & $\mathbf{1 0 0 \%}$ \\
$\quad$ Ranking & $4^{\text {th }}$ & $\mathbf{5}^{\text {th }}$ & $\mathbf{7}^{\text {th }}$ & $\mathbf{2}^{\text {nd }}$ & $\mathbf{1}^{\text {st }}$ & $\mathbf{3}^{\text {rd }}$ & $\mathbf{6}^{\text {th }}$ &
\end{tabular}

Source: Field work, (2013). Question 4, 5 and 6 of the questionnaire administered. 
A Review of Manufacturing Smes in Nigeria

Table 7. Calculation of correlation.

\begin{tabular}{ccccccccc}
\hline Options & High (6) & Slightly High (5) & Medium (4) & Slightly Low (3) & Low (2) & No Influ. (1) & No Opin. (0) & Total \\
\hline Points (x) & 6 & 5 & 4 & 3 & 2 & 1 & 0 & $\mathbf{2 1}$ \\
Response (y) & 14 & 13 & 10 & 78 & 860 & 16 & 11 & $\mathbf{1 0 0 2}$ \\
$\mathbf{x y}$ & 84 & 65 & 40 & 234 & 1720 & 16 & 0 & $\mathbf{2 , 1 5 9}$ \\
$\mathbf{x}^{2}$ & 36 & 25 & 16 & 9 & 4 & 14 & 0 & $\mathbf{1 0 4}$ \\
$\mathbf{y}^{2}$ & 196 & 169 & 100 & 6,084 & 739,600 & 256 & 121 & $\mathbf{7 4 6 , 5 2 6}$ \\
\hline
\end{tabular}

Source: Field work, (2013).

$$
\begin{aligned}
r & =\frac{N \sum x y-\left(\sum x\right)\left(\sum y\right)}{\sqrt{N \sum x^{2}-(x)^{2}} \sqrt{N \sum y^{2}-(y)^{2}}}=\frac{7(2159)-(21 \times 1002)}{\sqrt{(7 \times 104)-(21)^{2}} \sqrt{7 \times 746526-(104)^{2}}} \\
& =\frac{15113-21042}{\sqrt{(728-441)(5225682-10816)}}=\frac{-5929}{\sqrt{(287)(5214866)}}=\frac{-5929}{38687} \quad r=-0.1533(15 \%)
\end{aligned}
$$

\section{Hypothesis 3}

$\mathrm{H}_{0}$ : There is no significant association between LSS implementation and profitability of MSMEs in Nigeria.

$\mathrm{H}_{1}$ : There is significant association between LSS implementation and profitability of MSMEs in Nigeria.

\begin{tabular}{|c|c|c|c|c|c|c|c|c|}
\hline QN & Questionnaire & $\mathbf{H}$ & SLH & $\mathbf{M}$ & NO & SL & $\mathbf{L}$ & NI \\
\hline 7 & My management is committed to LSS implementation & 15 & 25 & 67 & 324 & 556 & 10 & 5 \\
\hline 8 & Workers participation on LSS implementation is high & 9 & 8 & 41 & 411 & 509 & 9 & 15 \\
\hline 9 & Size of resources is adequate to implement LSS & 1 & 2 & 5 & 325 & 626 & 32 & 12 \\
\hline 10 & LSS has improved MSMEs customer satisfaction & 6 & 5 & 100 & 279 & 566 & 12 & 34 \\
\hline 11 & LSS is responsible for high sales volume achieved & 2 & 2 & 5 & 6 & 105 & 869 & 13 \\
\hline \multirow[t]{4}{*}{12} & LSS is responsible for MSMEs high profitability & 1 & 2 & 4 & 3 & 87 & 802 & 103 \\
\hline & Total & 34 & 44 & 222 & 1,348 & 2448 & 1,734 & 182 \\
\hline & Average & 6 & 7 & 37 & 225 & 408 & 289 & 30 \\
\hline & Ranking & $7^{\text {th }}$ & $6^{\text {th }}$ & $4^{\text {th }}$ & $3^{\text {th }}$ & $1^{\text {st }}$ & $2^{\text {nd }}$ & $5^{\text {th }}$ \\
\hline
\end{tabular}

Table 8. Summary of responses of questions 7 to 12 .

Source: Field work, (2013).

Table 9. Calculation of correlation.

\begin{tabular}{ccccccccc}
\hline Options & High (6) & Slightly High (5) & Medium (4) & Slightly Low (3) & Low (2) & No Influ. (1) & No Opin. (0) & Total \\
\hline Points (x) & 6 & 5 & 4 & 3 & 2 & 1 & 0 & $\mathbf{2 1}$ \\
Response (y) & 6 & 7 & 37 & 225 & 408 & 289 & 30 & $\mathbf{1 0 0 2}$ \\
$\mathbf{x y}$ & 34 & 37 & 148 & 674 & 816 & 289 & 0 & $\mathbf{1 , 9 9 8}$ \\
$\mathbf{x}^{2}$ & 36 & 25 & 16 & 9 & 4 & 14 & 0 & $\mathbf{1 0 4}$ \\
$\mathbf{y}^{2}$ & 1,156 & 1,369 & 21,904 & 454,276 & 665,856 & 83,521 & 0 & $\mathbf{1 , 2 2 8 , 0 8 2}$ \\
\hline
\end{tabular}

Source: Field work, (2013).

$$
\begin{aligned}
r & =\frac{N \sum x y-\left(\sum x\right)\left(\sum y\right)}{\sqrt{N \sum x^{2}-(x)^{2}} \sqrt{N \sum y^{2}-(y)^{2}}}=\frac{7(1988)-(21 \times 1002)}{\sqrt{(7 \times 104)-(21)^{2}} \sqrt{7 \times 1228082-(104)^{2}}} \\
& =\frac{13986-21042}{\sqrt{(728-441)(8596574-10816)}}=\frac{-7056}{\sqrt{(287)(8585758)}}=\frac{-7056}{49640} \quad r=-0.1421(14 \%)
\end{aligned}
$$

